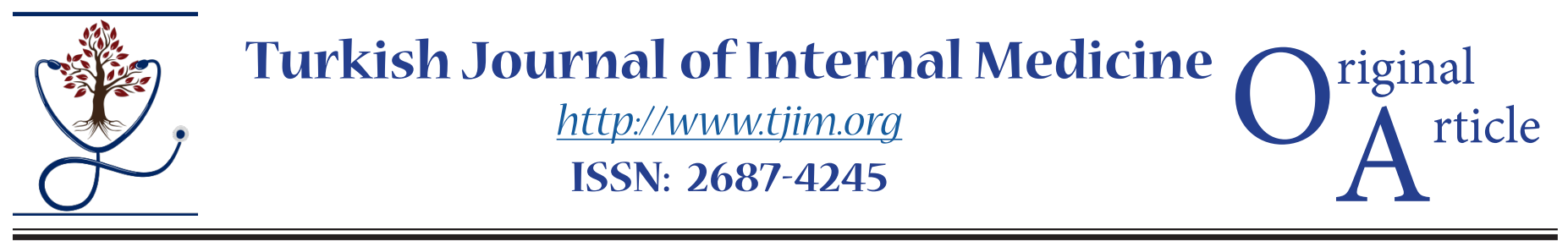

\title{
Early Experience of Kidney Transplantation in a New Center
}

\author{
Murat ÖZTÜRK ${ }^{1}$ (D), Atilla SATIR ${ }^{1}$ (D), Cuma Bülent GÜL ${ }^{2}$ (DD, Nizameddin KOCA ${ }^{3}$ (D) \\ ${ }^{1}$ University of Health Sciences, Bursa Yuksek Ihtisas Training and Research Hospital, Department of Urology, Bursa, Turkey \\ ${ }^{2}$ University of Health Sciences, Bursa Yuksek Ihtisas Training and Research Hospital, Department of Internal Medicine, \\ Division of Nephrology, Bursa, Turkey \\ ${ }^{3}$ University of Health Sciences, Bursa Yuksek Ihtisas Training and Research Hospital, Department of Internal Medicine, Bursa, \\ Turkey
}

\begin{abstract}
Introduction

Kidney transplantation is one of the most important treatments in end stage renal disease (ESRD). We aimed to share our experiences in 60 (57 deceased donors, 3 living donors) kidney transplantation cases performed in our center between July 2017 and August 2020.

\section{Material and Methods}

The demographic data of 60 patients with kidney transplantation performed in our kidney transplant center were evaluated in terms of causes and duration of renal failure human leucocyte antigen (HLA) tissue compatibility, immunosuppressive protocol used, antimicrobial agents, rejection status, graft loss, patient loss, postoperative surgical complications.

Results

Fifty-seven of our kidney transplants were made from deceased donors and 3 from living donors. The mean age of the patients was 44.66 (23-68) years. Kidney transplantation was performed in 8 patients (13.33\%) in the preemptive period. The mean number of mismatches in kidney transplants was $3.95(2-5)$ and the mean duration of renal replacement therapy (RRT) was 54.73 (0-270) months. While the mean follow-up period after transplantation was 18.86 (2-37) months, it was observed that the mean cold ischemia time was 742.8 (60-1080) minutes. Serum creatinine levels of 56 patients with functional grafts at the end of the first month $1.39(0.5-$ 4.9) $\mathrm{mg} / \mathrm{dL}, 54$ patients at the end of the sixth month, creatinine levels 1.29 (0.56-5.9) $\mathrm{mg} / \mathrm{dL}$, The creatinine levels of the 52 patients as of October 2020 were $1.37(0.75-5.16) \mathrm{mg} / \mathrm{dL}$. As surgical complications, hematoma developed in 5 patients $(8.33 \%$ ) and lymphocele in 3 patients (5\%). Early graft loss developed in one patient with renal artery embolism and two patients with renal vein thrombosis, while chronic rejection developed in two patients. We performed a deceased kidney transplant again 14 months later in a patient who developed graft loss in the early period due to renal vein thrombosis. The kidney inserted later is functional in the $10^{\text {th }}$ postoperative month. One of our patients died due to rhino-orbital mucor mycosis in the postoperative $2^{\text {nd }}$ month, and one patient due to the development of sepsis due to infection in the hip prosthesis in the postoperative $6^{\text {th }}$ month, while another patient died due to myocardial infarction in the postoperative $2^{\text {nd }}$ month.
\end{abstract}

\section{Conclusions}

As a result, our kidney transplant center is in development. Our results obtained from 60 kidney transplants, almost all of which were performed from deceased donors, seem to be compatible with the literature. More detailed results can be obtained with the long-term follow-up results and the increase in the number of living donor transplants.

Keywords: kidney transplantation, rejection, graft loss

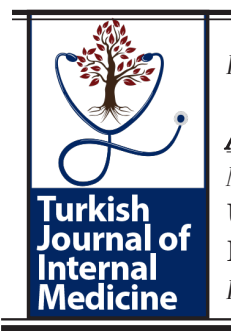

Received:October 15,2020;Accepted:October 24,2020; Published Online: October 29,2020 


\section{Introduction}

Organ transplantation is a life-saving treatment option for patients with end-stage renal disease (ESRD). Compared to the number of patients waiting for transplantation, the insufficient number of donors is the most important limiting factor of transplantation. ${ }^{1,2}$ Organ transplantation is a condition provided by the transplantation of organs taken from living donors or deceased donors to the recipient after brain death. ${ }^{3-5}$

There has been a significant increase in the number and success rate of kidney transplants with the development of drugs that prevent/treat rejection and effective antimicrobial therapy. Due to these developments, there has been a decrease in the incidence of acute rejection and a remarkable increase in graft survival rates. For these reasons, kidney transplantation has become the preferred renal replacement therapy (RRT) in the treatment of ESRD, as it both prolongs the survival and increases the quality of life. ${ }^{6}$

The first successful kidney transplant in the world was performed in 1954. In our country, Haberal et al. performed the first successful living donor and the first deceased donor kidney transplant in 1975 and 1978, respectively. ${ }^{4,7}$

The number of kidney transplants performed in our country has been increasing in recent years. According to the Ministry of Health data, a total of 3,861 kidney transplants were performed from 3,054 deceased donors and 807 living donors in $2019 .{ }^{8}$ In our country, when compared to the number of patients receiving RRT due to ESRD, it is observed that the number of transplants is far below the desired.

The sharing of the first experiences of the newly established transplant centers may be beneficial in terms of raising the awareness of the physicians who will work in the new centers about the risks and possible situations related to the transplants, as well as determining the issues that will be taken into consideration by the bodies authorized to establish the center.

Kidney transplantation has become the preferred treatment option in the treatment of ESRD due to both survival advantage and high quality of life, along with developments in immunology, and the use of new immunosuppressive and antimicrobial drugs..$^{9,10}$

Compared to dialysis, successful kidney transplantation is superior in terms of both life expectancy and quality of life. ${ }^{11-13}$ In this study, it is aimed to share our experience with 60 kidney transplantation performed in the kidney transplant center of the University of Health Sciences, Bursa Yüksek Ihtisas Training and Research Hospital (established in July 2017), in the light of the literature.

\section{Material and Methods}

Sixty kidney transplant cases (57 from deceased donors, 3 from living donors) performed in our transplant center between July 2017 and August 2020 were evaluated retrospectively, after the local ethical committee approval (2011-KAEK-25 2019/02-05). Organs were taken from deceased donors that emerged in hospitals in 5 provinces affiliated to Bursa regional coordination unit, whose brain death was declared, and organ donations were made. The selection of all kidney transplant recipients was made by the delegation formed by the regional coordination unit under the national coordination unit in line with the organ sharing criteria.

Organ extraction from donors was done by the same team. After the potential recipients were informed about the risks of the surgery by the transplant team, their consent was obtained. Demographic data, immunosuppressive protocol, rejection status, graft or patient loss, intraoperative or postoperative surgical complications and infection status were evaluated.

Transplant surgeries were performed by the same team. Left kidneys taken from the donor were placed in the right iliac fossa, and the right kidneys were placed in the left iliac fossa. An end-to-side anastomosis was made from the renal artery to external iliac or common iliac artery, and the renal vein to the external iliac vein. Ureteroneocystostomy was performed using extravesical technique (Lich-Gregoir). A $12 \mathrm{~cm}$ $4.8 \mathrm{~F}$ double $\mathrm{J}$ ureter catheter was used in all cases.

Deceased donors were considered to be at high immunological risk, and polyclonalantithymocyte globulin (ATG) were given to the recipients in a total of $9 \mathrm{mg} / \mathrm{kg}$ (peroperative 3 $\mathrm{mg} / \mathrm{kg} /$ day for induction and $1.5 \mathrm{mg} / \mathrm{kg} /$ day on the following days). In maintenance treatment, triple immunosuppressive therapy consisting of prednisone $(500 \mathrm{mg}$ peroperative, $20 \mathrm{mg} /$ day 
postoperative $6^{\text {th }}$ day, $5 \mathrm{mg} /$ day postoperative $6^{\text {th }}$ month), tacrolimus (TAC) $[(0.15 \mathrm{mg} / \mathrm{kg})$, target serum level $8-10 \mathrm{ng} / \mathrm{mL}$ for the first 3 months, then 5-7 $\mathrm{ng} / \mathrm{mL}$ ) and mycophenolate mofetil (MMF) (2 g/day) was preferred. In living donor transplants, those with low risk were given 1.5-2.5 mg ATG for 3 days and continued with TAC + MMF treatment. High risk patients were given ATG at the same dose for 5 days and continued with TAC + MMF treatment.

All patients received trimethoprim/ sulfamethoxazole and oral nystatin for nine months and valganciclovir for three months for infection prophylaxis.

\section{Results}

The demographic characteristics of the recipients and diseases causing ESRD are given in Table 1. While the mean age of all patients was 44.66 (23-68 years), $25(41.66 \%)$ of the patients were male and 35 (58.33\%) were female. Although the mean duration of RRT was $54.73(0-270)$ months, preemptive kidney transplantation was performed in 8 patients $(13.33 \%)$. The average number of HLA mismatches in kidney transplants performed is $3.95(2-5)$.

The average operation time was 225 (160-400) minutes and it was observed that the average duration of our last 10 operations decreased to 195 (160-225) minutes with the increased in experience. The mean follow-up time after transplantation was 18.86 (2-37) months, and the mean cold ischemia time was 742.8 (60-1080) minutes. While the mean serum creatinine levels of the patients with functional grafts in the first and sixth months were 1.39 (0.5-4.9) $\mathrm{mg} / \mathrm{dL}$ and $1.29(0.56-5.9) \mathrm{mg}$ / $\mathrm{dL}$, respectively, the mean creatinine levels of 52 patients with functional grafts were 1.37 (0.755.16) $\mathrm{mg} / \mathrm{dL}$ by October 2020.

As a standard protocol, a $12 \mathrm{~cm} 4.8 \mathrm{~F}$ double $\mathrm{J}$ catheter was placed in each recipient and removed on an average of 30 days. As surgical complications, hematoma developed in five patients $(8.33 \%)$, and lymphocele developed in three patients $(5 \%)$. The hematoma that developed in two patients was evacuated, three wound infections were treated with incision and drainage. One of 3 lymphoceles (10.3\%) was treated with percutaneous drainage and two with fenestration. Developing complications are given in Table 2.

One patient with renal artery embolism and two patients with renal vein thrombosis developed graft loss in the early period and chronic rejection was observed in two patients. We performed a deceased kidney transplant again 14 months later in our patient who developed graft loss in the early period due to renal vein thrombosis. After the

Table 1. Demographic characteristics of the recipients $(n=60)$

\begin{tabular}{lc}
\hline Variables & Values \\
\hline Gender (males/females) & $25 / 35$ \\
Age (years) & $44.66(23-68)$ \\
RRT duration (month) & $54.73(0-270)$ \\
HLA mismatch (number) & $3.95(2-5)$ \\
Preemptive (n, \%) & $8(\% 13.33)$ \\
Follow-up duration (month) & $18.86(2-37)$ \\
Cold ischemia duration (minutes) & $742.8(60-1080)$ \\
Primary diseases & $23(38.33)$ \\
Hypertension & $9(15)$ \\
Diabetes Mellitus & $7(11.66)$ \\
Polycystic kidney disease & $6(10)$ \\
Urolithiasis & $4(6.66)$ \\
Vesicoureteral reflux & $1(3.44)$ \\
Glomerulonephritis & $1(1.66)$ \\
Amyloidosis & $1(1.66)$ \\
Oxalosis & $1(1.66)$ \\
Systemic lupus erythematosus & $1(1.66)$ \\
Sjogren syndrome & $6(10)$ \\
Unknown &
\end{tabular}

Values are given as $\mathrm{n}(\%)$ or mean (min-max). RRT: renal replacement therapy, HLA: human leucocyte antigen. 
Table 2. Developed complications and their treatment in recipients

\begin{tabular}{lcl}
\hline Complication & $\mathbf{n}(\%)$ & \multicolumn{1}{c}{ Treatment } \\
\hline Lymphocele & $3(5)$ & $\begin{array}{l}\text { Percutaneous drainage }(\mathrm{n}=1) \\
\text { Fenestration }(\mathrm{n}=2)\end{array}$ \\
Arterial embolus & $1(1.66)$ & Graft nephrectomy \\
Hematoma & $5(8.33)$ & Evacuation \\
Wound Infection & $3(5)$ & Incision-drainage \\
Venous thrombosis & $2(3.33)$ & Graft nephrectomy \\
\hline
\end{tabular}

second transplant, the blood creatinine level was $1.1 \mathrm{mg} / \mathrm{dL}$ in the $10^{\text {th }}$ postoperative month.

A total of three recipient died after kidney transplantation. One of our patients died as a result of rhino-orbital mucormycosis in the postoperative $2^{\text {nd }}$ month, a patient died of the development of sepsis from the hip prosthesis infection in the postoperative $6^{\text {th }}$ month, and a patient died after myocardial infarction in the postoperative $2^{\text {nd }}$ month. Kidney functions were normal in all three cases.

\section{Discussion}

The most important problem in front of organ transplantation is the inability to provide enough organ donors. In our country, as of 2020, 21,686 people are waiting in line for deceased kidney transplantation. ${ }^{8}$ According to the Ministry of Health data, $21 \%$ of kidney transplants in our country in 2019 were performed from deceaseds. ${ }^{8}$ While $95 \%$ of our transplants have been carried out from deceased donors since the opening of our center, in March 2019, the first living donor kidney transplant was successfully performed in our center. Until today, we have performed kidney transplantation with living donors for 3 people with the experience we have gained in transplantations with deceased donors. In living donor transplants, patients were discharged after an average of 6 days because of functioning kidney in the early postoperative period. Donors were discharged on the $4^{\text {th }}$ postoperative day.

Yakupoglu et al. ${ }^{7}$ evaluated 79 patients, 64 from living donors and 15 from deceased donors, in their study, and reported the mean serum creatinine of 76 patients with functional grafts as $1.24 \mathrm{mg} / \mathrm{dL}$ at the end of the first month. Reported lymphocele in 4 patients, venous thrombosis in 2 patients, arterial thrombosis in 2 patients, urinary leakage in 1 patient, hematoma in 2 patients, and wound infection in 6 patients. Ay et al. ${ }^{14}$ evaluated 115 kidney transplant patients, 103 from living donors and 12 from deceased donors, and evaluated oneyear graft and patient survival rates as $98.3 \%$ and $100 \%$, respectively. Researchers also reported graft loss in 4 cases, ureteral stenosis in 1 case, and lymphocele in 5 cases. Krajewski et al. ${ }^{15}$ evaluated postoperative urological complications in their study of 460 cases, ureteral stenosis, lymphocele, nephroureterolithiasis and urethral stenosis were detected in $38(8.2 \%), 10(2 \%), 5(1 \%)$, and $5(1 \%)$ cases, respectively. In our study, 3 patients $(10.3 \%)$ developed lymphocele, one patient was treated with percutaneous drainage and the other two patients with fenestration. The hematoma that developed in five patients was drained, and three wound infections were treated with incision and drainage. The complication rates in the current study are slightly higher than the literature, which can be explained by the low rate of living donors $(95 \%$ [ $n=57]$ of our transplants were made from deceased donors).

Kidney transplants performed in the preemptive period (before dialysis treatment begins) have positive effects on both patient and graft survival and cost compared to kidney transplants performed after dialysis treatment begins. Especially, living donor kidney transplants are recommended to be performed in preemptive patients. ${ }^{16}$ In our center, $13.33 \%$ of kidney transplants have been done to patients in preemptive period. Increasing this rate will increase our success rates.

As a result, the number of organ transplant centers is increasing day by day in our country. Most of these centers work under general surgery clinics. In fewer centers, kidney transplants are performed by urologists. It is important that urologists, who successfully perform all kidney and bladder-related surgeries, be more active in kidney transplant surgeries. The interest of more urologists in this field can be increased 
by establishing transplantation training units as a sub-branch of urology in universities. The statistics of about 3 years in our relatively newly established center will become more meaningful with increased living donor transplants and longer follow-up.

\section{Conflict of interest}

The authors declared that there are no potential conflicts of interest with respect to the research, authorship, and/or publication of this article.

\section{References}

1. Ojo AO, Heinrichs D, Emond JC, McGowan JJ, Guidinger MK, Delmonico FL, Metzger RA. Organ donation and utilization in the USA. Am J Transplant. 2004;4 Suppl 9:27-37. doi: 10.1111/j.1600-6135.2004.00396.x.

2. Dare AJ, Bartlett AS, Fraser JF. Critical care of the potential organ donor. Curr Neurol Neurosci Rep. 2012 Aug;12(4):456-65. doi: 10.1007/s11910-012-0272-9.

3. Çolakoglu M, Nalbant M. Cadaver Organ Harvesting in Denizli. Turkish Nephrology Dialysis and Transplantation Journal 2005;14(3):123-6 (in Turkish).

4. Tuncer M, Gürkan A, Yücetin L, Ersoy F, Demirbas A, Akaydin M, Yakupoglu G. Evaluation of transplantation in one center: Akdeniz University model. Transplant Proc. 2002 Sep;34(6):2012-3. doi: 10.1016/s0041-1345(02)028336.

5. Kalayoglu M. Starting a liver transplant program in Turkey; Akdeniz University model. Turk J Gastroenterol. 2008 Mar;19(1):1.

6. Wolfe RA, Ashby VB, Milford EL, Ojo AO, Ettenger RE, Agodoa LY, Held PJ, Port FK. Comparison of mortality in all patients on dialysis, patients on dialysis awaiting transplantation, and recipients of a first cadaveric transplant. N Eng1 J Med. 1999 Dec 2;341(23):1725-30. doi: 10.1056/NEJM199912023412303.

7. Yakupoglu YK, Özden E, Koçak B, Dilek M, Akpolat T, Arık N, Cengiz K, Adıbelli Z, Özkaya O, Durupınar B, Tülek NE, Danacı M, Ceylan L, Sarıkaya S. Three years of kidney transplantation experience at an university hospital. Turkish Nephrology Dialysis and Transplantation Journal 2009;18(2):76-81 (in Turkish).

8. Avaliable at: https://organ.saglik.gov.tr. Accessed October 12, 2020.

9. Murray JE, Merrill JP, Harrison JH. Renal homotransplantation in identical twins. 1955. J Am Soc Nephrol. 2001 Jan;12(1):201-4.

10. Merrill JP, Murray JE, Harrison JH, Guild WR. Successful homotransplantation of the human kidney between identical twins. JAMA. 1984 May 18;251(19):2566-71. doi: 10.1001/jama.251.19.2566.

11. Suthanthiran M, Strom TB. Renal transplantation. N Engl J Med. 1994 Aug 11;331(6):365-76. doi: 10.1056/ NEJM199408113310606.

12. Port FK, Wolfe RA, Mauger EA, Berling DP, Jiang K. Comparison of survival probabilities for dialysis patients vs cadaveric renal transplant recipients. JAMA. 1993 Sep 15;270(11):1339-43.

13. Ay N, Anıl M, Alp V, Sevük U, Dinç B, Çelik M, Danıs R. Evaluation of quality of life early and late after kidney transplantation. Ann Transplant. 2015 Aug 25;20:493-9. doi: 10.12659/AOT.895139.

14. Ay N, Kaya S, Çiçek N, Bahadır MV. A single centre experience of renal transplantation in Diyarbakir. Dicle Medical Journal 2017 Jun 1;44(2):199-204 (in Turkish).

15. Krajewski W, Dembowski J, Kolodziej A, Malkiewicz B, Tupikowski K, Matuszewski M, Chudoba P, Boratynska M, Klinger M, Zdrojowy R. Urological complications after renal transplantation - a single centre experience. Cent European J Urol. 2016;69(3):306-311. doi: 10.5173/ ceju.2016.833.

16. Liem YS, Weimar W. Early living-donor kidney transplantation: a review of the associated survival benefit. Transplantation. 2009 Feb 15;87(3):317-8. doi: 10.1097/TP.0b013e3181952710. 